\title{
Effects of the cryolipolysis using the advanced redux method in the treatment of localized adiposity
}

\author{
Roseane Débora Barbosa Soares', Rodrigo Marcel Valentim da Silva², Júlio Costa e Silva ${ }^{3}$, Bruna Figueiredo Pinto ${ }^{3}$, Stephany \\ Queiroga Farias ${ }^{3}$, Ana Lívia Eufrázio de Medeiros Farias³ ${ }^{3}$ Eneida de Morais Carreiro ${ }^{4}$, Claudete Arruda Maciel de Queiroz5, \\ Patrícia Froes Meyer ${ }^{3}$
}

\begin{abstract}
Background: Among the techniques used in clinical practice to reduce localized adiposity, cryolipolysis has been highlighted, which is a non-invasive method capable of reducing the thickness of the adipose tissue without damage to the surrounding tissues. However, several associations of techniques suggest an intensification of the results, associating cryolipolysis with other treatments, and the most common is ultracavitation (UCV) or radiofrequency (RF) and massage. Objective: To investigate the effects of cryolipolysis associated with UCV and RF on localized adiposity. Methods: This is a blinded and controlled clinical trial. The sample was composed of 30 females divided into 2 groups of 15: one group received cryolipolysis application in the abdominal region, and performed 1 session of drainage weekly; while another group performed the cryolipolysis and then 8 applications of UCV associated with RF and modeling massage (protocol named Advanced Redux Method-ARM), once a week. The parameters used in cryolipolysis were: temperature: -7으; suction pressure: $30 \mathrm{kpa}$; and application time: $50 \mathrm{~min}$. For the UCV, the parameters were time of 8 minutes, $30 \mathrm{w}$ of potency and intensity of $10 \mathrm{w} / \mathrm{cm}^{2}$. After cryolipolysis, a follow-up of 2 months was performed to verify the changes related to weight, perimeter and thickness of the adipose tissue, measured by ultrasonography. The reassessments were performed 30 and 60 days after the cryolipolysis. Results: It was observed that the ARM promoted a greater reduction of adiposity located in the abdominal region, in the plicometry, perimetry and ultrasonography variables $(p<0.05)$. In the analysis of the questionnaires the ARM group showed lower edema, pain, ecchymosis after application when compared to the group associated only with the drainage. The percentage of satisfaction was also higher in the ARM group. Conclusion: Therefore, it can be observed that the association of UCV, RF and modeling massage through the ARM promoted a higher reduction in adiposity than the group that exclusively performed the cryolipolysis treatment with lymphatic drainage.

Keywords: Adipose Tissue; Cryotherapy; Mechanical Waves; Electromagnetic Field.
\end{abstract}

\section{INTRODUCTION}

Cryolipolysis is one of the most commonly used techniques for the treatment of localized adiposity in clinical practice. Its effects are already widely reported in the literature, and it is observed that lipid-rich tissues are more susceptible to injury by the cold. Thus, thermal modulation promotes selective lesions on the adipocytes of the subcutaneous region, avoiding damage to the epidermis and dermis, providing an effective way of treating excess localized adipose tissue ${ }^{(1,2)}$. This technique promotes different responses in the adipose tissue, generating systemic responses in the organism, interfering in the thermal equilibrium and activating the mechanisms of thermoregulation. Tests made with adipocytes in vitro, in order to know the behavior of them in relation to the cold, showed that temperatures below zero would cause apoptosis in these cells. This suggests that cryolipolysis produces an apoptotic death in adipose tissue after exposing the tissue to cold for a period of 30 to 60 minutes. In addition, the subsequent inflammatory response caused additional damage to adipocytes not immediately affected by the exposure to the cold ${ }^{(2,3)}$. Following the genetic program, it is observed that the death of the frozen cells triggers a controlled autodigestion process, followed by removal of the damaged cells without alteration of the cellular microenvironment ${ }^{(4,5)}$. In the search for intensification of these adiposity reduction responses using cryolipolysis, new treatment associations are emerging in the market, among which ultracavitation (UCV) is one of the frequently used noninvasive techniques. UCV consists of a high-intensity ultrasonic wave-emitting apparatus, which selectively induces the formation of bubbles in fat cells. These bubbles expand and compress (cavitation) due to pressure changes in tissue fluids, promoting shock between adipocytes and rupture of their membranes

Corresponding Author: Rodrigo Marcel Valentim da Silva. Address: Rua Nossa Senhora de Fátima, 312 b, Alecrim, Natal (RN), Brasil. Telephone: +55 (84) 99517077. E-mail: marcelvalentim@hotmail.com

2 Faculdade de Excelência do Rio Grande do Norte (ESTÁCIO - FATERN), Natal (RN), Brasil.

Full list of author information is available at the end of the article.

Financial support: The authors declare that there was no financial support.

Submission date 27 August 2018; Acceptance date 10 October 2018; Publication date 28 November 2018 
(lipolysis). In addition, this technique is associated with radiofrequency (tissue heating) and modeling massage $\mathrm{e}^{(6-8)}$. Another resource used to treat adiposity is radiofrequency (RF), a technique that uses a high-frequency electromagnetic field, which promotes vibration of the molecules and heating of tissues. It is suggested that the RF favors the increase of adipose tissue metabolism, as well as the destruction of the cellular plasma membrane. In clinical practice has been observed a frequent association of cryolipolysis with $\mathrm{RF}$, however, few studies verify its effects ${ }^{(9-11)}$. In addition, it is suggested that the association with manual massage is a resource that contributes to the improvement of the clinical outcome of the cryolipolysis procedure. The reperfusion of the tissue contributes to the tissue reorganization during the inflammatory response after cryolipolysis ${ }^{(12,13)}$.

However, there is still a need for more scientific evidence to verify the effects of this association of cryolipolysis with UCV, as well as with RF and modeling massage. The use of this association of techniques and physical agents as a treatment after the application of cryolipolysis has received in clinical practice the name of Advanced Redux Method (ARM), therefore, this study aims to describe the response of cryolipolysis associated with UCV, and RF and modeling massage to reduce localized adiposity.

\section{METHODS}

This is a blinded, randomized and controlled trial. This study was submitted to the Research Ethics Committee of the Universidade Potiguar - UnP (CEP-UNP), protocol number 2.530.976. The present research followed the ethical aspects of the Resolution 453/2012 of the National Health Council, and the Declaration of Helsinki. All volunteers agreed to participate in the study and signed the Informed Consent Form, which presented the information about the purposes, risks and benefits of the research. The 30 volunteers, who were treated with an application of cryolipolysis in the abdominal region, were selected by non-probabilistic convenience. The inclusion criteria were: female; 25 to 45 years old; sedentary and presenting abdominal localized adiposity; with body mass index (BMI) between 18.5 and 29.99 (Normal to Overweight); with localized fat in the infraumbilical region greater than $15 \mathrm{~mm}$ (identified by ultrasound); and who were not taking medicines with lipolytic and/or thermogenic effects until 1 week before the start of the study. All subjects who presented allergic reaction prior to cold, peripheral circulatory diseases and Raynaud's syndrome were excluded from the study. Two volunteers dropped out the research. The sample was recruited in a non-probabilistic way through the website "www.randomization.com", and randomly distributed in two groups color coded. The researchers were also divided into 2 groups: the researchers in group 1 were responsible for the evaluation and those in group 2 were responsible for the intervention. The coding was under the responsibility of the Researcher Group 1 so they did not know which procedure they were submitted. The intervention protocols were performed by the Researcher Group 2 to guarantee the study blindness.

The instrument to collect data for this research was the Physiotherapeutic Evaluation Protocol for Localized Adiposity ${ }^{(14)}$ (PAFAL), validated by Meyer et al $(2008)^{(15)}$, in which the following topics were addressed: identification; anamnesis; smoking; physical examination; and measures and tests such as: weight, height, BMI, skinfolds and measures of circumference. It was used the ultrasound device MSLPU35 Linear Wireless Probe Ultrasound Scanner (10MHZ), manufactured by Guangzhou Medsinglong Medical Equipment Co., and which analyzes and measures adipose tissue. After the volunteers signed the Form, they were submitted to the PAFAL for the data collection and anthropometric data evaluation. Perimetry was performed using a Fiber tape and making the circumference measurement $5 \mathrm{~cm}$ below the umbilical scar. The plicometry was performed with a Sanny plicometer (American Medical do Brasil Ltda, São Paulo, Brazil) that has a measurement range of 0 to $65 \mathrm{~mm}$. The skinfold was measure three times in the left infraumbilical region, and the result was based on the mean of these values. Subsequently, they were submitted to the ultrasound examination that was performed by a medical specialist. The volunteer was in the dorsal position and the transducer was positioned in the pendent form, perpendicular to the cutaneous tissue, without pressure on the skin in order to avoid influences on the result. The examination was performed on the infraumbilical region, in an area of $10 \mathrm{~cm}^{2}$ located $2 \mathrm{~cm}$ below the umbilical scar. Photos were taken from the front, left profile and right profile of the volunteers in standing position. Neutral color background was used to obtain standardized images. It was used a Galaxy J5 Prime camera, manufactured by Samsung. The body weight was measured with the volunteer standing on the scale, wearing underwear. It was used a Sanny digital scale.

The volunteers were assessed 3 times during the study: before and after 30 and 60 days; using the perimetry, plicometry, photographs, body weight, ultrasonographic analysis and satisfaction questionnaire adapted from the questionnaire of Segot-chicq et al, $(2007)^{12}$. The volunteers were divided into two groups: G1, which performed cryolipolysis and massage immediately after for 5 minutes and after a week started manual lymphatic drainage (MLD) treatment except on the abdominal region performed once a week for 08 weeks; $\mathrm{G} 2$, which performed cryolipolysis and massage immediately after for 5 minutes and after that it was performed 08 applications of ultracavitation + radiofrequency + modeling massage (ARM) once a week. The evaluations 
were performed before the cryolipolysis procedure, after 30 days of the procedure, and after 4 MLD sessions in the G1 and after 4 ARM sessions in the G2. The cryolipolysis was applied with the patient in dorsal decubitus position on a stretcher with $45^{\circ}$ of inclination. It was used the Advice Cryotop redux device. The applicator was placed on the same place where the ultrasonography was performed and the parameters used were: temperature of $-7^{\circ} \mathrm{C}$ and suction pressure of $30 \mathrm{Kpa}$, application time of 50 minutes. The MLD treatment was performed for 25 minutes in dorsal decubitus on lower limbs and lower back. The ARM treatment consisted of continuous UCV at $70 \%$ intensity for 10 minutes and continuous RF at $60 \%$ intensity for 10 minutes, followed by 5 minutes of modeling massage on the infra-umbilical region for mobilization of connective tissue. The RF instrument used was the CECBRA (CEC BRA Equipamentos Eletrônicos para Medicina e Estética Ltda., Jaraguá do Sul, SC, Brazil) and the UCV was CECBRA/lipocavit (CEC BRA Equipamentos Eletrônicos para Medicina e Estética Ltda., Jaraguá do Sul, $\mathrm{SC}$, Brazil).

\section{Statistical Analysis}

After the treatment and final evaluation and reassessment, the descriptive and inferential statistical analysis of the data was performed through SPSS 22.0 (Statistical Package for the Social Science- version 22.0, Armonk, USA). The normality of the data distribution was observed by the Kolmogorov-Smirnov test (KS). For descriptive analysis was used the mean as central tendency measure and the standard deviation as dispersion measure. For inferential statistics, the two-way repeated-measures analysis of variance (ANOVA) was used to verify differences between the groups before and after the interventions. In all statistical analysis it was assigned a significance level of $5 \%$ and a confidence interval of $95 \%$ (IC 95\%). Qualitative data (descriptive analysis of the ultrasound images) were described based on medical reports.

\section{RESULTS}

Initially 30 volunteers were recruited, however, during the research procedures, there were 2 dropouts in the control group. Table 1 presents mean values, standard deviation and inferential analysis between the control and treated groups.

It was observed that the final right and left plicometry and final ultrasonography variables showed a significant reduction in the group that performed the MRA after cryolipolysis when compared to the group that only performed the cryolipolysis with MLD.

In relation to ultrasonography, the images demonstrate this significant difference in the ARM group as shown in Figures $1 \mathrm{~A}, 1 \mathrm{~B}$ and $1 \mathrm{C}$, which present the results of the ultrasound analyzes of the pre-treatment evaluation, evaluation after 30 days (04 ARM sessions) and after 60 days (08 ARM sessions).

The volunteer of Figures $1 \mathrm{~A}, \mathrm{~B}$ and $\mathrm{C}$ presented a significant reduction in adipose tissue mainly in the second evaluation. It is possible to notice the result through the Figure $2 \mathrm{~A}$ and $2 \mathrm{~B}$. Regarding the group that used manual

Table 1: Analysis of variables related to localized adiposity.

\begin{tabular}{|c|c|c|c|}
\hline & Drainage & ARM & $P$ value \\
\hline Weight 1 & $62.24 \pm 4.85$ & $64.8 \pm 5.91$ & 0.70 \\
\hline Weight 2 & $65.76 \pm 5.9$ & $65.29 \pm 4.9$ & 0.89 \\
\hline Weight 3 & $64.56 \pm 6.8$ & $64.5 \pm 6.5$ & 0.99 \\
\hline Plico D1 & $26.07 \pm 12.12$ & $30.2 \pm 9.44$ & 0.35 \\
\hline Plico D2 & $26.14 \pm 11.32$ & $23 \pm 9.55$ & 0.07 \\
\hline Plico D3 & $23 \pm 15.17$ & $21.2 \pm 9.19$ & $0.001 *$ \\
\hline Plico E2 & $28.64 \pm 12.2$ & $30.66 \pm 9.55$ & 0.41 \\
\hline Plico E2 & $29.5 \pm 12.2$ & $31.46 \pm 9.63$ & 0.27 \\
\hline Plico E3 & $26.31 \pm 16$ & $24.31 \pm 10.3$ & $0.001 *$ \\
\hline Peri 1 & $90.46 \pm 6.38$ & $89.6 \pm 8.55$ & 0.32 \\
\hline Peri 2 & $88.9 \pm 5.7$ & $86.29 \pm 8.0$ & 0.34 \\
\hline Peri 3 & $87.82 \pm 6.1$ & $86.3 \pm 6.1$ & 0.81 \\
\hline US & $1.3 \pm 0.9$ & $1.4 \pm 80.8$ & 0.13 \\
\hline US 2 & $1.08 \pm 0.9$ & $0.9 \pm 0.5$ & $0.05^{*}$ \\
\hline
\end{tabular}

Note: $\mathrm{ARM}=$ Advanced Redux Method; Plico= Plicometry; Peri= Perimetry; US= Ultrasound. 

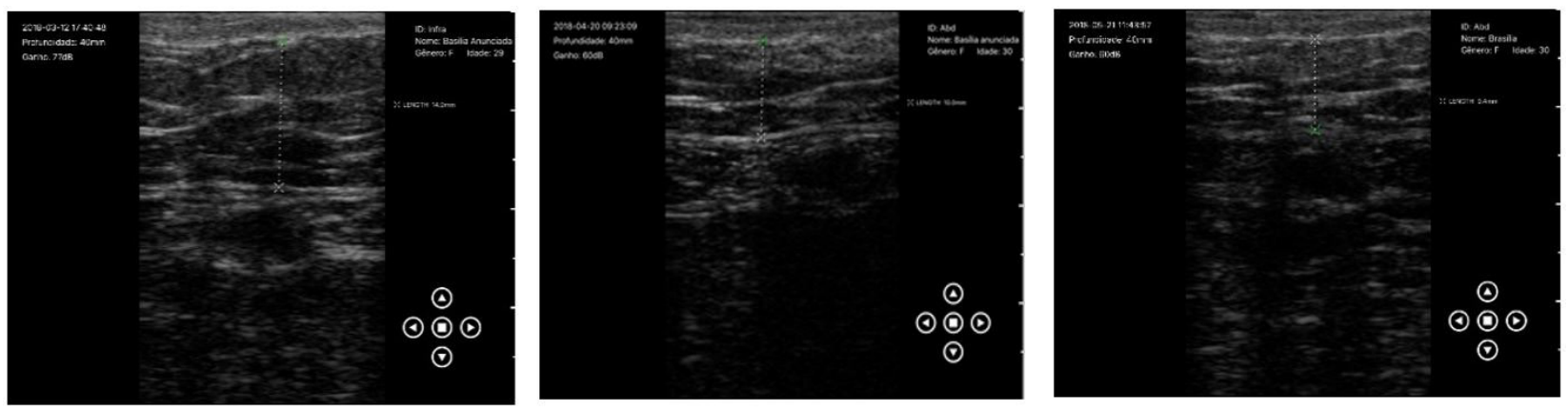

A

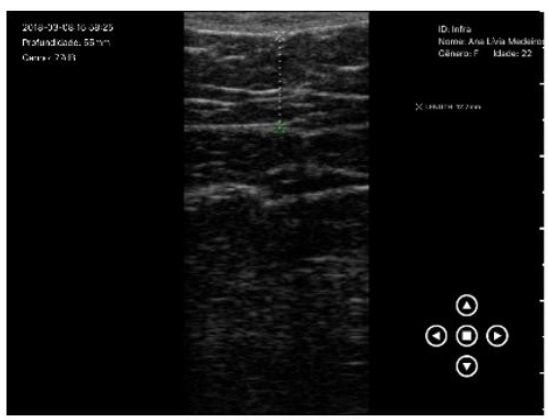

D
B

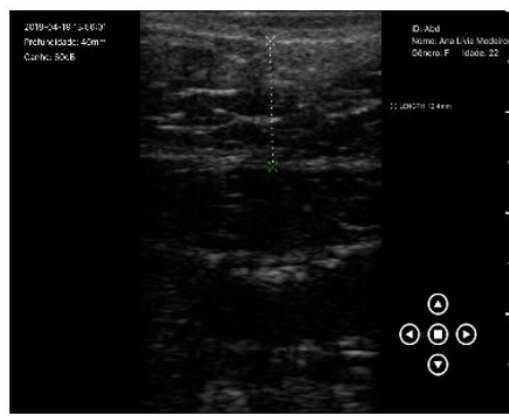

E
C

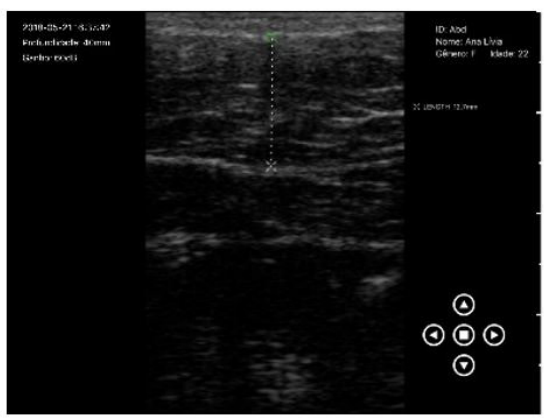

F

Figures 1: A, B and C: Results of volunteer submitted to Advanced Redux Method after cryolipolysis, presenting adipose tissue thickness of 1.49cm (before), 1cm after 30 days of treatment and $0.94 \mathrm{~cm}$ after 60 days of treatment. D, F and G: Results of volunteer submitted to manual lymphatic drainage after cryolipolysis, presenting adipose tissue thickness of $1.27 \mathrm{~cm}$ (before), $1.24 \mathrm{~cm}$ after 30 days of treatment and $1.27 \mathrm{~cm}$ after 60 days of treatment.

lymphatic drainage, the results were not significant, as shown in figures 1D, 1F and 1G, which represent the ultrasonographic analyzes of a volunteer submitted to this technique after cryolipolysis. In the case of the second volunteer who belonged to the group of MLD after cryolipolysis, there was no difference in relation to the reduction of the adipose tissue thickness as occurred in several cases of volunteers submitted to the same conduct. It is not possible to notice this difference in figures $2 \mathrm{C}$ and $2 \mathrm{D}$.

Table 2 presents the results of the application of the satisfaction questionnaire applied to volunteers.

It was observed that in the analysis of pain perception (mild to severe) $73.3 \%$ of the volunteers in the MRA group did not report pain and the same proportion reported dormancy. About $46.7 \%$ of the volunteers in the ARM group found satisfactory the treatment outcome. It was observed that about $80 \%$ of the volunteers in the ARM group did not present edema, ecchymosis and hematomas, but presented considerable erythema. In the aesthetic improvement scale, it was observed that the number of volunteers (percentage) in the ARM group who reported 'greatly improvement' and 'better' was greater than in the MLD group.

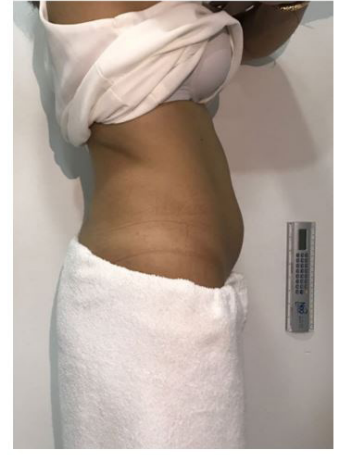

A

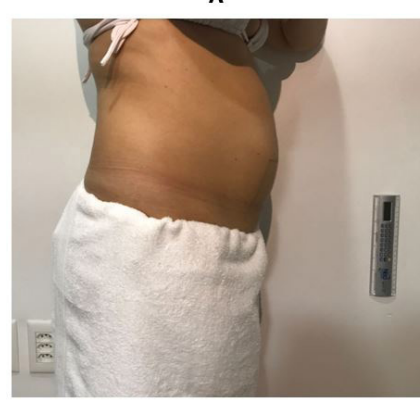

C

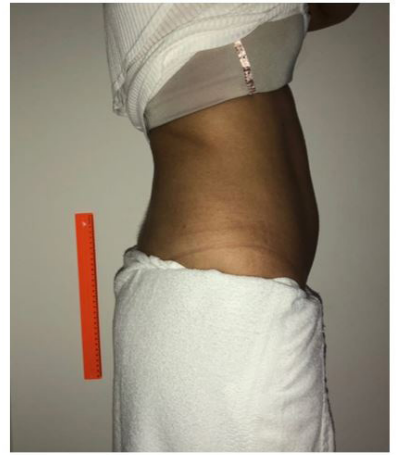

B

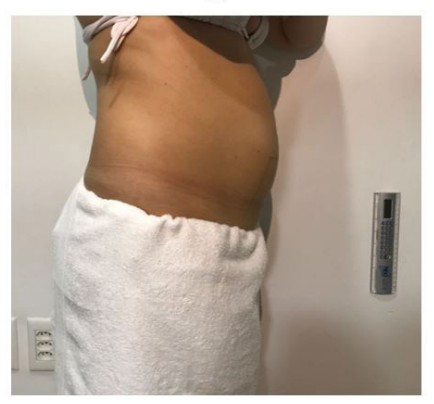

D
Figure 2: Photographic record of the volunteers in the comparison between first and third evaluation. 
Table 2: Distribution of absolute and relative frequencies of the satisfaction questionnaire.

Pain (mild to severe)

MLD

Yes

No

ARM

Yes

No

Numbness or decreased sensitivity

MLD

Yes

ARM

Local hypersensitivity

MLD

Yes

ARM

Edema/swelling/transient localized bubbles

\section{MLD}

Yes

ARM

Yes

Erythema (redness) post-session

\section{MLD}

Yes

ARM

Yes

Ecchymosis/Temporary hematoma

\section{MLD}

Yes

ARM 
Table 2: Continued...

\section{Burns}

MLD

Yes

No

ARM

Yes

No

Abnormal growth of fat at the treatment region

\section{MLD}

Yes

No

ARM

Yes

No

She sought medical help to solve an adversities

MLD

Yes

No

ARM

Yes

No

She was satisfied with the result obtained

MLD

Yes

No

ARM

Yes

No

Scale of aesthetic improvement

MLD

Greatly improvement

Much improvement

ARM

Greatly improvement

Note: $M L D=$ manual lymphatic drainage; $A R M=$ Advanced Redux Method.

\section{DISCUSSION}

It was observed that both techniques promoted the reduction of localized adiposity, however the use of the ARM promoted a greater reduction when compared to the group that exclusively performed the application of the MLD technique after cryolipolysis. Several noninvasive techniques have been used to reduce localized adiposity as an alternative to surgical procedures, among them: massage, shock waves, UCV and RF. However, little has been described in the literature on the association of cryolipolysis with these techniques ${ }^{(1,3,8)}$. 
The ARM consists of the combination of a cryolipolysis application with 8 sessions of UCV, RF and modeling massage, performed once a week for 8 weeks.

Performing the massage of connective tissue on the treated region promotes a reperfusion of the tissue in which cryolipolysis has been applied. It is suggested that the thermal modulation generated by the manual technique on the subcutaneous tissue promotes an intracellular lipid crystallization which favors the destruction of adipocytes. This rapid rise in temperature promotes a greater influx of inflammatory cells and mediators, leading to further destruction of adipose tissue cells ${ }^{(14,15)}$. The association with UCV may have favored the reduction of localized adiposity. The UCV consists of the emission of mechanical waves that promote the phenomenon of cavitation and intensify the destruction of adipose tissue ${ }^{(16,17)}$. It is observed that the UCV performed in an isolated way already presents significant results of the reduction of the perimetry, plicometry and in the analysis of the ultrasonography, being thus used in clinical practice $^{(18)}$. In addition, the analysis performed on rabbits has also demonstrated reduced fat cell concentration as well as reduced adipocyte volume ${ }^{(19)}$. In clinical practice, with the previously association of cryolipolysis and the UCV, it was observed a reduction in waist circumference and suprailiac skin fold. The combination with RF promotes the increase in temperature in the deep tissues associated with vasodilatation, increases blood and lymphatic circulations, increases diffusion through the cell membrane, increases metabolism and enzymatic activity, among others ${ }^{(20)}$. This combination may also be important to increase the prolonged response of apoptosis and destruction of adipose tissue, which favors the reduction of this tissue ${ }^{(8)}$. Thermal damage of adipose tissue occurs selectively as result of the electric field with other methods of non-invasive fat reduction, serious adverse events are rarely associated with $\mathrm{RF}^{(21)}$. It is observed that the group that associated cryolipolysis with lymphatic drainage did not present a reduction of the localized adiposity. Lymphatic drainage does not promote adiposity reduction, the association with cryolipolysis aims to reduce excess fluid in biological tissue ${ }^{(22,23)}$. The combination of cryolipolysis, UCV and RF techniques has demonstrated a greater reduction of adipose tissue, since the three techniques promote biological responses on the fat cells with destruction of these cells or reduction of their concentration ${ }^{(24-26)}$. In addition to the reduction of adiposity, ARM showed improvements in the analyzes performed after the intervention, such as reduction of edema in the application zone and increase of erythema. These factors may characterize a more rapid inflammatory process that favors the reduction of localized adiposity. On the other hand, the presence of hematomas and ecchymoses after the application was higher in the drainage group than the ARM, indicating a faster healing response ${ }^{(25-28)}$. It was verified that both groups reported in the questionnaire of perception of aesthetic improvement high percentages of 'best', 'much improvement' or 'greatly improvement', but the group that performed ARM had a higher percentage of these values compared to the group of MLD after the crilipolysis. This study presented as a limitation the non-accomplishment of a histopathological analysis of the treated adipose tissue, suggesting the realization of new studies that can do this analysis in humans or animals.

\section{CONCLUSION}

Therefore, it can be observed that the association of ultracavitation, radiofrequency and modeling massage through the Advanced Redux Method promoted a higher reduction in adiposity than the group that exclusively performed the cryolipolysis treatment with manual lymphatic drainage.

\section{AUTHORS' CONTRIBUTIONS}

RMVS and PFM elaborated the study design; JCS, RDBS and BFP performed the data collection; SQF, ALEMF and RMVS performed the statistical analysis; EMC, CAMQ and PFM performed the critical, intellectual revision of the manuscript. All authors read and approved the final manuscript.

\section{CONFLICT OF INTEREST}

The authors declare that there was no conflict of interests.

\section{AUTHORS DETAILS}

1 Faculdade de Ciências Médicas do Piauí, FACIME, Teresina (PI), Brasil.

${ }^{3}$ Universidade Potiguar - UNP, Natal (RN), Brasil.

${ }^{4}$ Centro Universitário do Rio Grande do Norte - UNI-RN, Natal (RN), Brasil.

${ }^{5}$ Centro Universitário de João Pessoa, João Pessoa (PB), Brasil.

\section{REFERENCES}

1- Lipner SR. Cryolipolysis for the treatment of submental fat: Review of the literature. J Cosmet Dermatol. 2018;17(2):145-151.

2- Derrick CD, Shridharani SM, Broyles JM. The Safety and Efficacy of Cryolipolysis: A Systematic Review of Available Literature. Aesthet Surg J. 2015;35(7):830-6.

3- Munavalli GS, Panchaprateep R. Cryolipolysis for Targeted Fat Reduction and Improved Appearance of the Enlarged Male Breast. Dermatol Surg. 2015;41(9):1043-51.

4- Krueger N, Mai SV, Luebberding S, Sadick NS. Cryolipolysis for noninvasive body contouring: clinical efficacy and patient satisfaction. Clin Cosmet Investig Dermatol. 2014;26;7:201-5.

5- Friedmann DP. A review of the aesthetic treatment of abdominal subcutaneous adipose tissue: background, implications, and therapeutic options. Dermatol Surg. 2015;41(1):18-34.

6- Quistgaard Ju. The European Aesthetic Guide Spring 2010. Available from: http://digital.miinews. com/publication/?i=34631\&page=1

7- Nassab R. The Evidence Behind Noninvasive Body Contouring Devices. Aesthet Surg J. 2015;35(3):279-93.

8- Mulholland RS, Paul MD, Chalfoun C. Noninvasive body contouring with radiofrequency, ultrasound, cryolipolysis, and low-level laser therapy. Clin Plast Surg. $2011 ; 38(3): 503-20$.

9- Friedmann DP. A review of the aesthetic treatment of abdominal subcutaneous adipose tissue: background, implications, and therapeutic options. Dermatol Surg. $2015 ; 41(1): 18-34$. 
10- McDaniel D, Fritz K, Machovcova A, Bernardy J. A focused monopolar radiofrequency causes apoptosis: a porcine model. J Drugs Dermatol. 2014;13(11):1336-40

11- Boisnic S, Divaris M, Nelson AA, Gharavi NM, Lask GP. A clinical and biological evaluation of a novel, noninvasive radiofrequency device for the long-term reduction of adipose tissue. Lasers Surg Med. 2014 ;46(2):94103.

12- Boey GE, Wasilenchuk JL. Enhanced clinical outcome with manual massage following cryolipolysis treatment: a 4-month study of safety and efficacy. Lasers Surg Med. 2014 ;46(1):20-6.

13- Sasaki GH, Abelev N, Tevez-Ortiz A. Noninvasive selective cryolipolysis and reperfusion recovery for localized natural fat reduction and contouring. Aesthet Surg J. 2014;34(3):420-31.

14- Segot-Chicq E, Compan-Zaouati D, Wolkenstein P, Consoli S, Rodary C, Delvigne V, Guillou V, Poli F. Development and validation of a questionnaire to evaluate how cosmetic product for oily skin is able to improve wellbeing in women. J Eur Acad Dermatol Venereol. 2007 ;21(9):1181-6.

15- Meyer PF, Furtado ACG, Morais SFT, de Araujo Neto LG, Silva RMV, Medeiros ML, Queiroz., CAM. Effects of Cryolipolysis on Abdominal Adiposity of Women. Cryoletters. 2017;38 (5):379-386(8).

16- Sasaki GH; Abelev N; Tevez-Ortiz A. Noninvasive selective cryolipolysis and reperfusion recovery for localized natural fat reduction and contouring. Aesthetic Surgery Journal. 2014;34(3):420-431.

17- Ferraro GA, De Francesco F, Nicolettl G, Rossano F, D’andrea F. Histologic effects of external ultrasound-assisted lipectomy on adipose tissue. Aesthetic Plast Surg 2008;32(1):111-5.

18- Eldesoky E E, Mohamed AG, Samir MM. Ultrasound cavitation versus cryolipolysis for non-invasive body contouring. Australasian J Derm. 2016, 57 (4): 288-93
19- Silva RMV, Meyer PF, Santos BR, Oliveira Félix, JL, Ronzio OA. Efectos del ultrasonido de alta potência en la adiposidad localizada. Fisioterapia. 2015;37(2): 55-59.

20- Meyer PF, Carvalho MGF, Andrade LL, Lopes RNS, Delgado AM, Araújo HG, Nóbrega LLM, Nóbrega MM, Barrichelo PA, Silva RMV. Efeitos da ultracavitação no tecido adiposo de coelhos. Fisioter. Bras;2012;13(2):106111.

21- Ronzio AO, Meyer PF, Medeiros TD, Gurjão JB. Efectos de latransferenciaelectrica capacitiva eneltejidodermico y adiposo. Fisioterapia. 2009;31(4):131-136.

22- Vanaman, Monique, Guillen, Sabrina Fabi, Carruthers, Jean Carruthers. Complications in the Cosmetic Dermatology Patient: A Review and Our Experience. American Society for Dermatologic Surgery,2016;4 2: 1.

23- Gonçalves CS, Madeira JC, Silva MDD. Terapia combinada associada à drenagem linfática reduz lipodistrofia localizada no abdômen de mulheres jovens. ConScientiae Saúde, 2017;16(2): 281-288.

24- Miwa H, Kino M, Han LK, Takaoka K, Tsujita T, Furuhata $\mathrm{H}$ et al. Effect of ultrasound application on fat mobilization. Pathophysiology. 2002;(9): 13-19.

25- Vieira Nunes M, Costa Silva, F, Ramiro Moreira JA. Criolipólise: pré e póstratamento eletroterapêutico. Fisioterapia Brasil 2018;18.6:750-56.

26- Lipner SR. Cryolipolysis for the treatment of submental fat: Review of the literature. J Cosmet Dermatol. 2018;17(2):145-151.

27- Ortiz AE, Avram MM. Noninvasive body contouring: cryolipolysis and ultrasound. Semin Cutan Med Surg. 2015;34(3):129-33.

28- Loap S, Lathe R. Mechanism Underlying Tissue Cryotherapy to Combat Obesity/Overweight: Triggering Thermogenesis. J Obes. 2018; 5789647. 